\title{
Med-index: a food product labeling system to promote adherence to the mediterranean diet encouraging producers to make healthier and more sustainable food products
}

\author{
Maria Lisa Clodoveo $^{1 *}$, Elvira Tarsitano ${ }^{2}$, Carlo Sabbà ${ }^{1}$, Loreto Gesualdo ${ }^{3}$, Filomena Corbo ${ }^{4}$ \\ ${ }^{1}$ Interdisciplinary Department of Medicine, Piazza Giulio Cesare, University of Bari, Bari, Italy; ${ }^{2}$ Department of \\ Veterinary Medicine, University of Bari A. Moro, Bari, Italy; ${ }^{3}$ Department of Emergency and Organ Transplantation- \\ Piazza Giulio Cesare, University of Bari, Bari, Italy; ${ }^{4}$ Department of Pharmacy-Drug Sciences, University of Bari, Bari, \\ Italy
}

*Corresponding Author: Maria Lisa Clodoveo, Interdisciplinary Department of Medicine, Piazza Giulio Cesare, University of Bari, Bari, Italy. Email: marialisa.clodoveo@uniba.it

Received: 22 September 2021; Accepted: 4 November 2021; Published: 30 November 2021

(C) 2021 Codon Publications

OPEN ACCESS (C) (i) (ㄱ)

OPINION PAPER

\begin{abstract}
Consumers are increasingly demanding transparency in food labeling as they want more and better information about what they are eating and where their food comes from. Several food indexes have been developed in the last decades to promote healthy eating with the aim of reducing certain diseases such as obesity, cancer, and diabetes. The Mediterranean diet is known to be one of the healthiest dietary patterns, and it is associated with a lower incidence of mortality from all-causes, and it is also related to a lower incidence of cardiovascular diseases, type 2 diabetes, certain types of cancer, and neurodegenerative diseases; however, a comprehensive index that quantifies the Mediteraneaness of foods is still missing. The real European challenge is to identify a uniform labeling system for the whole of Europe which promotes a healthy lifestyle. This article describes the development of the Mediterranean Index (MI), which aims to accurately measure the degree of food Mediterraneaness. The MI simultaneously integrates nutritional and sustainability characteristics of foods. The MI may provide an objective basis for the use of the "Mediterraneaness" label on food products, which can ultimately promote adherence to the Mediterranean diet encouraging producers to make healthier and more sustainable food products. Growing consumer concern toward health foods for better health can be a factor useful to promote the applicability of the precision nutrition principles by means of conscious choice.
\end{abstract}

Keywords: disease prevention; front-of-pack nutrition label; healthy eating choices; Mediterranean diet; sustainable production.

\section{Introduction}

According to EU statistics, in 2017, over 950,000 deaths were attributable to unhealthy diets. Nutrientbased warning labels can help in finding healthy diets. Nutritional labeling, in fact, is a very important tool because it immediately provides consumers with the information necessary to compare one product with another and to assess whether or not it meets their dietary needs, allowing them to make an informed choice (Mhurchu et al., 2017). The goal is to develop a method to combat diseases related to incorrect eating habits (Joint WHO/FAO Expert Consultation, 2003). The nutritional profiles related to foods, in turn, serve to distinguish those unbalanced in the supply of energy, nutrients, and sodium. The nutritional profiles related to foods were introduced by the regulation on Nutrition \& Health Claims (Regulation (EC) No 1924/2006 of the European Parliament and of the Council of 20 December 2006) with the express purpose of preventing that HFSS 
foods (with high fat, sugar and sodium content) could boast alleged health benefits, protecting consumers from misleading communications that jeopardize a fair comparison between products.

As part of the "Farm to Fork Strategy," the path designed to lead toward a healthier and more sustainable food system, the European Commission intended to propose a compulsory nutritional labeling system harmonized at the EU level, which should be adopted by the end of 2022 . The European challenge is to identify a uniform labelling system for the whole of Europe, which is not penalizing but promotes a healthy lifestyle. The objectives of the Farm to Fork Strategy clearly recognize that our health begins with the quality of the food we eat. Promoting healthy eating also means practicing prevention to defeat certain diseases such as obesity, especially childhood obesity, cancer, and diabetes (no less important is to add "sustainability" as an additional quality to be certified through labels (Narciso and Fonte, 2021)).

Currently, in the European Union, there are four systems, three of which are based on colors but significantly different from each other. The first simplified nutrition label is the one adopted in June 2013 by Great Britain, which uses the three traffic light colors, taking as a reference the amount of calories, sugar, salt, fat, and saturated fat in $100 \mathrm{~g}$ of product. Color is applied to each of these ingredients, except for the calories. The usefulness of traffic lights is evident on HFSS foods.

The British traffic light labeling system (Figure 1) explains whether a food has high, medium, or low amounts of fat, saturated fat, sugars, and salt (Machín et al., 2018).

Then, there is the Nutri-Score label (Figure 2) adopted by France (Chantal et al., 2017), which expresses the overall nutritional quality of foods through the use of five colors, from green to red, which correspond to five letters of the alphabet, from "A" to the "E." The color is attributed to the food as a whole, considering the presence of ingredients and nutrients to be limited, such as simple sugars and salt, but also those positive for health, such as fibers, fruits, and vegetables.

Between these two systems adopted by the British and French governments was the initiative of six big names in the food industry-Nestlé, Coca-Cola, PepsiCo, Unilever, Mondelez, and Mars - who launched their own traffic light label (Julia and Hercberg, 2018), inspired by the British one, with an apparently insignificant difference but with important consequences. While the label adopted by Great Britain refers to the number of calories, sugar, salt, fat, and saturated fat referring to $100 \mathrm{~g}$ of product, that of the industries, called Evolved Nutrition Labeling, refers to a single portion, which however is established by the company.

Italy argues that the "traffic light" indications penalize the Mediterranean diet and more generally, therefore, the "Made in Italy" products. The proposed Italian alternative is called Nutrinform Battery (Lorenzoni et al., 2021) and evaluates not individual foods, but rather their incidence within the diet. The label is designed as a battery and indicates all the values relating to a single portion consumed. The symbol, therefore, indicates the percentages of energy, fats, saturated fats, sugars, and salt provided by the individual portions compared to the recommended daily amount. In practice, the percentage of energy or nutrients contained in the single portion is represented by the charged part of the battery, so as to visually quantify them.

Nutrinform battery (Figure 3) is considered a difficult system because it proposes a generic reference to the "portion" and uses a misleading image, as in the common logic if the battery is more charged it is better, but not in the case of fats, sugars and salt, for which the best solution is represented by a flat battery.
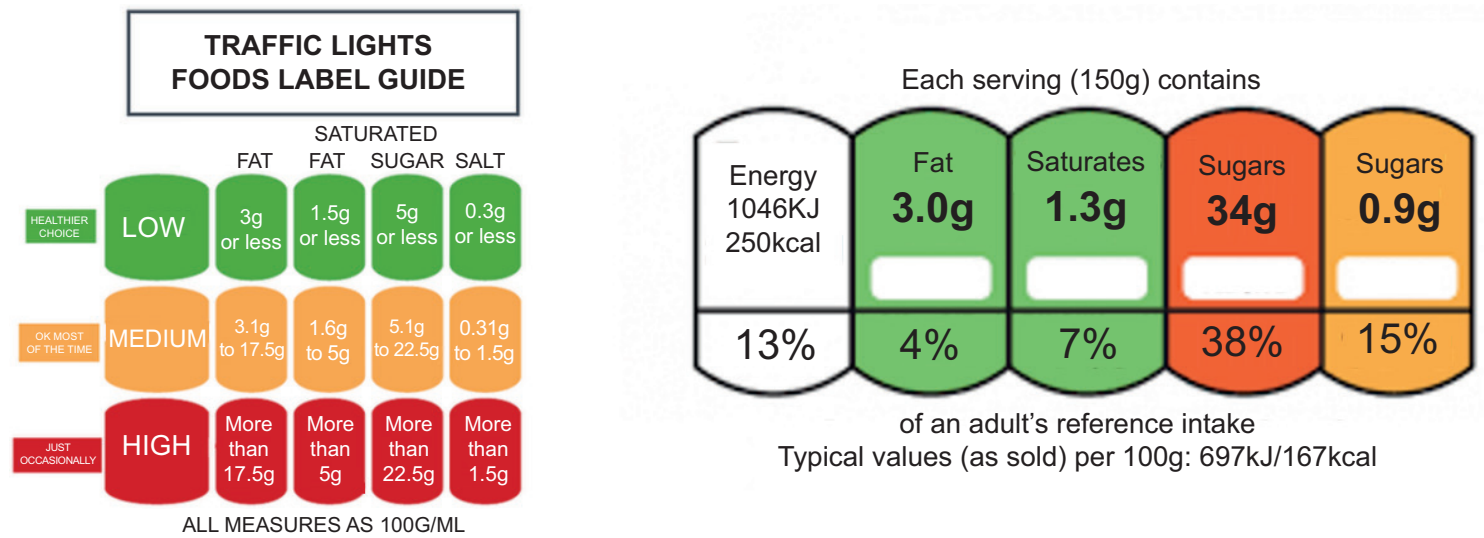

Figure 1. The British traffic light labeling system will tell you whether a food has high, medium, or low amounts of fat, saturated fat, sugars, and salt. 


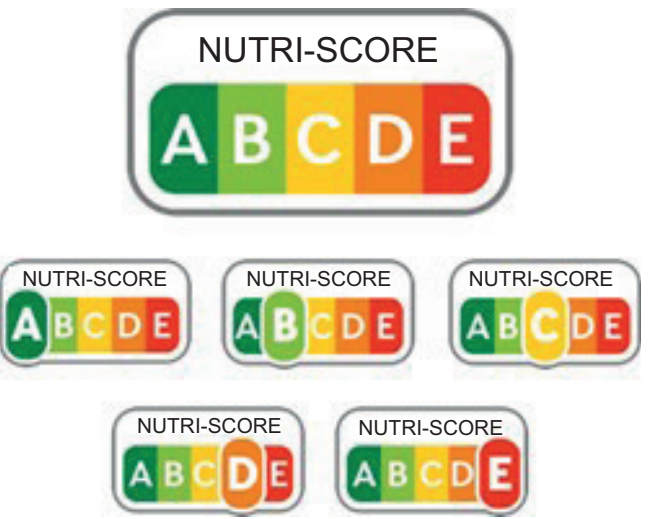

\begin{tabular}{c|c|c|c|c} 
Points & $\begin{array}{c}\text { Energy } \\
(\mathbf{k J})\end{array}$ & $\begin{array}{c}\text { Sugar } \\
(\mathbf{g})\end{array}$ & $\begin{array}{c}\text { Saturated } \\
\text { fatty acids }(\mathbf{g})\end{array}$ & $\begin{array}{c}\text { Sodium } \\
(\mathbf{m g})\end{array}$ \\
\cline { 1 - 4 } $\mathbf{0}$ & $\leq 335$ & $\leq 4.5$ & $\leq 1$ & $\leq 90$ \\
$\mathbf{1}$ & $>335$ & $>4.5$ & $>1$ & $>90$ \\
$\mathbf{2}$ & $>670$ & $>9$ & $>9$ & $>180$ \\
$\mathbf{3}$ & $>1005$ & $>13.5$ & $>13.5$ & $>270$ \\
$\mathbf{4}$ & $>1340$ & $>18$ & $>18$ & $>360$ \\
$\mathbf{5}$ & $>1675$ & $>22.5$ & $>22.5$ & $>450$ \\
$\mathbf{6}$ & $>2010$ & $>27$ & $>27$ & $>540$ \\
$\mathbf{7}$ & $>2345$ & $>31$ & $>31$ & $>630$ \\
$\mathbf{8}$ & $>2680$ & $>36$ & $>36$ & $>720$ \\
$\mathbf{9}$ & $>3015$ & $>40$ & $>40$ & $>810$ \\
$\mathbf{1 0}$ & $>3350$ & $>45$ & $>45$ & $>900$ \\
\hline Total & $\mathbf{1}$ point & $\mathbf{1}$ point & $\mathbf{1}$ point & $\mathbf{1}$ point \\
\hline
\end{tabular}

\begin{tabular}{|c|c|c|c|}
\hline Points & $\begin{array}{c}\text { Fruits, } \\
\text { vegetables (\%) }\end{array}$ & $\begin{array}{l}\text { Fibers } \\
\text { (g) }\end{array}$ & $\begin{array}{l}\text { Proteins } \\
\text { (g) }\end{array}$ \\
\hline 0 & $\leq 40$ & $\leq 0.9$ & $\leq 1.6$ \\
\hline 1 & $>40$ & $>0.9$ & $>1.6$ \\
\hline 2 & $>60$ & $>1.9$ & $>3.2$ \\
\hline 3 & - & $>2.8$ & $>4.8$ \\
\hline 4 & $=$ & $>3.7$ & $>6.4$ \\
\hline 5 & $>80$ & $>4.7$ & $>8.0$ \\
\hline Total & 0 point & 5 point & 5 point \\
\hline
\end{tabular}

(

\section{(}

Figure 2. The Nutri-Score is a nutrition label that converts the nutritional value of products into a simple code consisting of five letters, each with its own color. Each product is awarded a score based on a scientific algorithm.

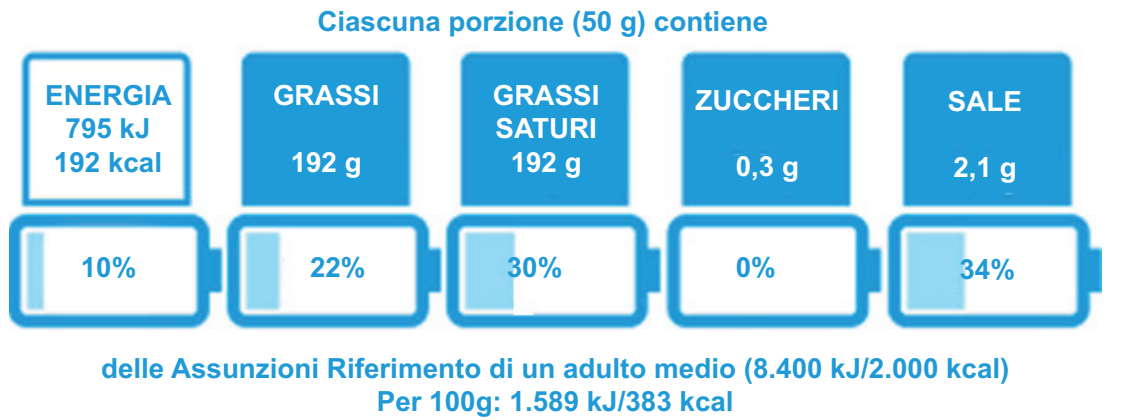

Figure 3. In the Nutrinform Battery nutrition label, each of the five batteries offers the consumer both a percentage and quantitative indication of the variable it represents (calories, sugars, etc.) in relation to a portion of the product to be purchased.

Both Nutri-Score (referred to $100 \mathrm{~g}$ of food) and Nutrinform Battery (referred to an arbitrary portion of food) essentially repeat what is already reported in the mandatory "nutritional declaration" reported in the rear part of the package in accordance with Regulation 1169/2011 starting from 13 December 2016, and do not constitute an effective tool for adapting the choices in relation to the quantitative and qualitative need of each individual.
National authorities of France, Belgium, Germany, Luxembourg, Netherlands, Spain, and Switzerland announced the establishment of a transnational coordination mechanism to facilitate the use of the front-ofpack nutrition label Nutri-Score.

Meanwhile, some member states of the EU (Italy, Czech Republic, Cyprus, Greece, Hungary, Latvia, and Romania, 
which could soon be joined by Poland and Slovakia), have set up a united front against Traffic Light Label/ Nutri-Score labels, considered a distorting element of the market that can cause economic and image damage to Mediterranean products and provide scarce benefits for consumers, as it does not represent an effective and complete tool to promote a healthy diet and a balanced eating style.

In the European single market, there are nutrition labeling systems that do not give "red cards" but are based on a positive classification, such as the "keyhole" label in force in the Scandinavian countries-Sweden, Norway, and Denmark (van der Bend and Lissner, 2019). The keyhole has only green, indicating healthy products, recognized on the basis of specific requirements.

\section{Not All "Calories" Are Created Equal}

It is well known that food molecules not only serve as nutrients but can also modulate the body's physiological functions (Chakrabarti et al., 2018; Rescigno et al., 2017; Vamanu and Gatea, 2020). One of the final goals of the promising field of precision nutrition is the design of nutritional recommendations tailored to treat or prevent metabolic disorders (Toro-Martín et al., 2017). More specifically, precision nutrition aims to develop more comprehensive and dynamic nutritional recommendations based on variable and interacting parameters in a person's internal and external environment throughout life (Toro-Martín et al., 2017).

Weight problems and obesity are increasing at a rapid rate in most of the EU Member States (Garrido-Miguel et al., 2019). Obesity is a serious public health problem, as it significantly increases the risk of chronic diseases such as cardiovascular disease, type-2 diabetes, hypertension, coronary heart diseases, and certain cancers (Frasca et al., 2017). For specific individuals, obesity may further be linked to a wide range of psychological problems. For society as a whole, it has substantial direct and indirect costs that put a considerable strain on healthcare and social resources.

Excess weight and obesity are in $95 \%$ of cases the result of an energy imbalance between calories input and calories consumed by the body (Romieu et al., 2017). The principles of thermodynamics applied to the energy of the human body show that the susceptibility to weight gain varies among individuals due to the inter-individual differences in energy expenditure and energy intake, two factors that balance and determine the daily energy balance and, ultimately, the change in body weight (Piaggi, 2019). Excess energy is stored by the body in the form of fat; therefore, the British traffic light label, the French Nutri-Score label, and the Italian Nutrinform Battery are strongly focused on calorie content in foods. The simplified representation of a food in absolute terms of calories is an oversimplification of the functioning of the human body which is not simply a machine that burns fuel. The human body decodes the introduced molecules and considers food, more than a source of plastic and energy molecules, above all, as a source of information.

As defined, a calorie is the amount of energy it takes to raise $1 \mathrm{~kg}$ of water by $1{ }^{\circ} \mathrm{C}$. However, the value of a food goes beyond calories, including macronutrients like fats, carbohydrates, and proteins, and micronutrients like vitamins, minerals, and antioxidants. So, consuming 100 calories of candy is not the same as consuming 100 calories of fruit, vegetables, and legumes that contain dozens of essential nutrients and tens of thousands of bioactive substances. So, food quality is more important than quantity. The nutrigenomics studies demonstrated that food molecules modify the extent to which different genes are expressed and thereby modulates the incidence of numerous chronic diseases linked to eating patterns. In fact, "food matrices" contain different compounds that interact in a coordinated way in the human body, determining the positive or negative effect of food. The researchers of European Nutrigenomics Organization support the hypothesis that all diseases can be reduced to imbalances in four overarching processes: inflammatory, metabolic, oxidative, and psychological stress. Diseases arise because of genetic predispositions to one or more of these stressors.

Food quality affects the first three of these four areas and explains the effects that two dietary patterns such as the Mediterranean Dietary Pattern (MDP) and Western Dietary Pattern (WDP) have on human health (Table 1). Moreover, food molecules are the main significant determinants of the microbial multiplicity of the gut and its metabolic activities.

Caloric restriction, understood as the pillar of the prevention of chronic noncommunicable diseases, is by no means the only discriminating factor as many studies have shown, in particular the European project PREDIMED (Martínez-González et al., 2015), which highlighted that in their primary prevention trial, an energy-unrestricted Mediterranean diet, supplemented with extra-virgin olive oil or nuts, resulted in a substantial reduction in the risk of major cardiovascular events among high-risk persons. These results can support the principles that the benefits of the Mediterranean diet for the primary prevention of cardiovascular disease are not exclusively dependent on the quantity of assumed foods but on the quality of the product that composed the basket of food choices. 
Table 1. Comparison among Mediterranean Dietary Pattern (MDP) and Western Dietary Pattern (WDP).

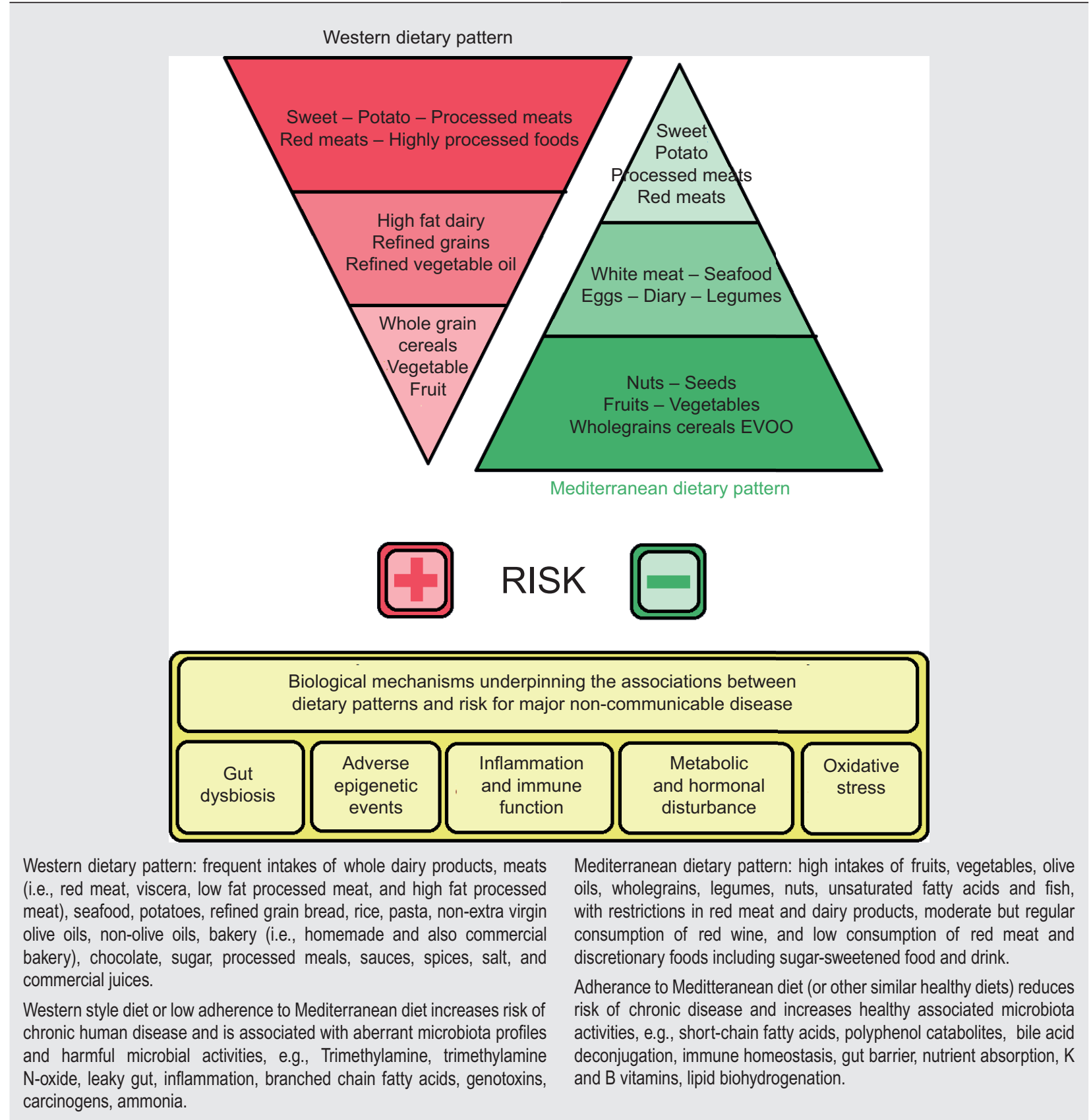

\section{The Diet for a Healthy Life in a Healthy Planet}

Sustainable diets have low environmental impact and contribute to food and nutrition security and a healthy life for present and future generations of human resources (Nelson et al., 2016). Europe enters the 2030 agenda for sustainable development with an ambitious policy document: the Green Deal (Haines and Scheelbeek, 2020). The objectives contained therein aim to promote the efficient use of resources by moving to a clean and circular economy, to restore biodiversity and reduce environmental pollution, promoting what is called "green transition," transforming the problems of climate and environmental challenges into opportunities across all sectors and making the transition just and inclusive for all (Sikora, 2021). Educating about the Mediterranean diet also means spreading and enhancing a sustainable consumption model capable of ensuring food security, promoting healthy lifestyles, sharing good food practices, and contributing to the achievement of the Sustainable Development Goals (SDGs) set by the UN 2030 Agenda and those established by the European Commission in the Green Deal (Dernini and Berry, 2015; Medina, 2021; Serra-Majem et al., 2020).

The real and progressive increase of the environment, climate, food, and health crisis of our century requires 
reconstructing the connections among agriculture, nutrition, and ecology. To be able to conjugate the "tradition" with the "technology" is a challenge of our millennium for the benefit of quality and sustainability of good life and well-being.

In 2015, the global community adopted the 17 Global SDGs to improve people's lives by 2030. Worth mentioning is the Goal 2-Zero Hunger-a commitment to end hunger, to achieve food security and improved nutrition, and promote sustainable agriculture. Actually, the world has made great progress in reducing hunger, but if we want to see a world free from hunger by 2030, governments, citizens, civil society organizations, and the private sector must work together to invest, innovate, and create lasting solutions through resilient communities. Reducing food waste is one of the major challenges faced by the Agenda 2030 through the Goal 12, "Ensuring sustainable production and consumption patterns." Worth mentioning too are ambitious targets that have been set out by the UN including the implementation of a 10-year framework of activities linked to sustainable production and consumption, aimed at reducing food loss by 2030, as well as along the entire food chain, and above all halving per capita food waste in terms of retail sales and domestic consumption (SDG 12.3).

\section{The Med-Index}

The Mediterranean Index (MI) has been developed as a tool to accurately measure the degree of food Mediterraneaness. The MI simultaneously integrates nutritional and sustainability characteristics of foods. The MI may provide an objective basis for the use of the "Mediterraneaness" label on food products, which can ultimately promote adherence to the Mediterranean diet among citizens, encouraging producers to make healthier and more sustainable food products.

"The Mediterranean way" through a food product labeling system (Med-Index) is, in fact, also a tool for achieving these goals of the 2030 Agenda for Sustainable Development. In fact, the Mediterranean diet and the MedIndex stimulate, in a simple and intuitive way, the interest of the community in a correct diet; it brings citizens closer to the productive world; it stimulates interest and curiosity from adults to younger groups so that they acquire greater awareness of the importance of sustainability as a primary tool for sustainable development, well-being, and good life for every society (de Vries, 2020; Tarsitano et al., 2020) by launching the foundations for the creation of a network of sustainable and resilient communities.

Combining tradition and innovation through the multifunctionality and diversification of agriculture such as the quality of products, rather than only production, reproducibility of resources, protection and valorization of the landscape, and cultural and ethical values in a perspective of sustainability is the real challenge Agriculture must return to open itself toward other knowledge, like new connections between air and water, earth and living organisms (vegetal and animal), because they represent the real foundation of ecological knowledge. It is about knowing, recognizing, and appreciating the ancient flavors of our agri-food tradition and trying to safeguard our different ecosystems throughout the Mediterranean area. The local product is linked to the land where it is produced, to its environmental resources, to its historical processes, to its community networks, and to people who live there.

Healthy eating is the most direct and complete way to relate to the surrounding world, to express our culture through the choice of food and the methods of consumption. It must be taken into account that the state of health of people, their equilibrium, and psycho-physical well-being are closely linked to the relationship with the environment in which they live and to interactions with others, including animals and plants, waters, smells and flavors: it would be like distancing people from their natural history, turning them away from ancestral experiences that linked them to the mother earth and shaped their tastes and choices, including food.

The distinctive character must be that of a sustainable, holistic, and systemic approach to healthy eating: we believe that lifestyle modifications and individual behavior can lead us on the path of awareness for the improvement of quality and sustainability of life. The Mediterranean diet/way adapts easily to changes by improving its current perception not only as a healthy diet but also as a sustainable lifestyle (Tarsitano et al., 2018).

"The Mediterranean way" and the correct adoption of the Med-Index becomes a model of resilient and sustainable communities (Table 2). Inspired by this sustainable, holistic, and systemic notion of the Mediterranean diet, the authors identify the importance of sustainable food culture, scientific research, training and creation of wide and comprehensive partnership networks, with the aim of developing instruments for the defense of human rights, such as the right to adequate nutrition for everyone, a healthy well-being and good life, an intact and healthy environment, as well as the respect for and enjoyment of common goods and specific cultural identities and biodiversity of the territories, including the food production according to principles of sustainability, dignity, and equity for all people involved.

Nutritional labeling should not only be a tool that provides the consumer with the information about 
Table 2. Elements of sustainability of the Mediterranean diet.

\section{Sustainability of the Mediterranean diet}

The Mediterranean food model is healthy for both people and the environment. It is estimated on average that to obtain 100 calories, the Mediterranean diet causes an environmental impact of about $60 \%$ less than a Western-style diet, based to a greater extent on meat and animal fats, rather than on vegetables and cereals.

The Mediterranean food model, as already underlined by UNESCO, goes beyond the concept of food. The term diet itself derives from the ancient Greek diaita (lifestyle) to indicate the social and cultural value of the Mediterranean diet. Considering the positive effects on the social, economic and environmental spheres, the Mediterranean diet can be considered a sustainable food model.

\section{ENVIRONMENTAL BENEFITS}

Use of natural resources. The Mediterranean diet involves a high consumption of cereals, fruit, vegetables and legumes, the production of which requires a less intensive use of natural resources (soil, water) and greenhouse gas emissions compared to a diet based mostly on the consumption of meat and animal fats. Seasonality. The Mediterranean diet provides for the consumption of food respecting the seasonality of the same. This translates into a reduction in greenhouse crops and related environmental impacts, as well as supply and transport costs from distant countries (food miles).

Biodiversity. The Mediterranean diet respects the territory and biodiversity, through different sowing in each area and crop rotation, in order to also guarantee food security.

Frugality. The Mediterranean diet includes moderate portions and consumption of whole and fresh, lightly processed foods. Both the quantities consumed and the minor transformations undergone by food contribute to reducing the environmental impacts of eating behaviors.

\section{SOCIAL BENEFITS}

Health. The Mediterranean diet, together with physical activity, helps prevent cardiovascular disease, diabetes and some types of cancer (colorectal, breast, prostate, pancreas, endometrium). In addition, the intake of fresh and whole foods allows greater availability and use of micronutrients and antioxidants.

Awareness. The Mediterranean diet promotes greater food awareness and link with the territory, knowledge of seasonality, biodiversity and naturalness of foods.

Conviviality. The Mediterranean diet promotes social interaction, common meals are the cornerstone of the holidays and of our social traditions.

Identity. The Mediterranean diet is an expression of the entire historical and cultural system of the Mediterranean. It is a millenary food tradition that has been handed down from generation to generation, promoting not only the quality of foods and their territorial characterization, but also the dialogue between peoples.

\section{ECONOMIC BENEFITS}

Health expenditure. A greater adherence of eating habits to the Mediterranean model would improve the general state of health of the population, which would translate into a decrease in national health expenditure.

Household spending. Adherence to the Mediterranean food model, favoring seasonal foods, mainly cereals and vegetables, would allow a decrease in household food spending.

Business enhancement. The spread of the Mediterranean food model would result in an increase in the commercial demand for natural products (fruit, vegetables, cereals, legumes ...) and their derivatives (olive oil, wine, pasta, bread ...), creating income and employment for companies in the Mediterranean regions.

Enhancement of territories. The spread of the Mediterranean food model would enhance the agro-enogastronomic offer of our territories, contributing to the seasonal adjustment of the tourist offer. nutritional needs but also an instrument to compare one product with another with the aim of assessing the element of sustainability because human health is inextricably linked to the health of the planet. In order to interrupt the information asymmetry that often characterizes food purchases and to offer the possibility of a better understanding of the information on the products useful for following a healthy and sustainable diet based on the principles of the Mediterranean diet, a new model of nutritional labeling, called Med Index, has been developed.

\section{Med-Index: The Shape}

Nutrition labeling must be able to speak to consumers by making immediately clear the purpose for which it was designed. The first phase of the design involved the choice of the geometric shape to be assigned to the label in such a way that it immediately and uniquely brings to mind the topic for which it is designed: information relating to nutritional aspects. The triangle is a symbol of action; it recalls the indications of the road signs and induces you to think about the direction to take. Geometric shapes quickly bring to mind past experiences. The triangle is immediately associated with the stable image of a mountain or a pyramid. Here, the food pyramid comes to mind and evokes the concepts of balanced food choices aimed at well-being. The dissemination of messages can also take place through forms and images; it is not necessary to add anything else, no words and no numbers.

The triangle, like the iconography of the food pyramid (Figure 4), has been divided into three parallel bands to identify two fields that return quantitative information to the user and one field for qualitative information.

The apex of the triangle (Figure 5) was intended to inform about the doses that make up the sales unit. The individual dose is defined by means of icons that identify 

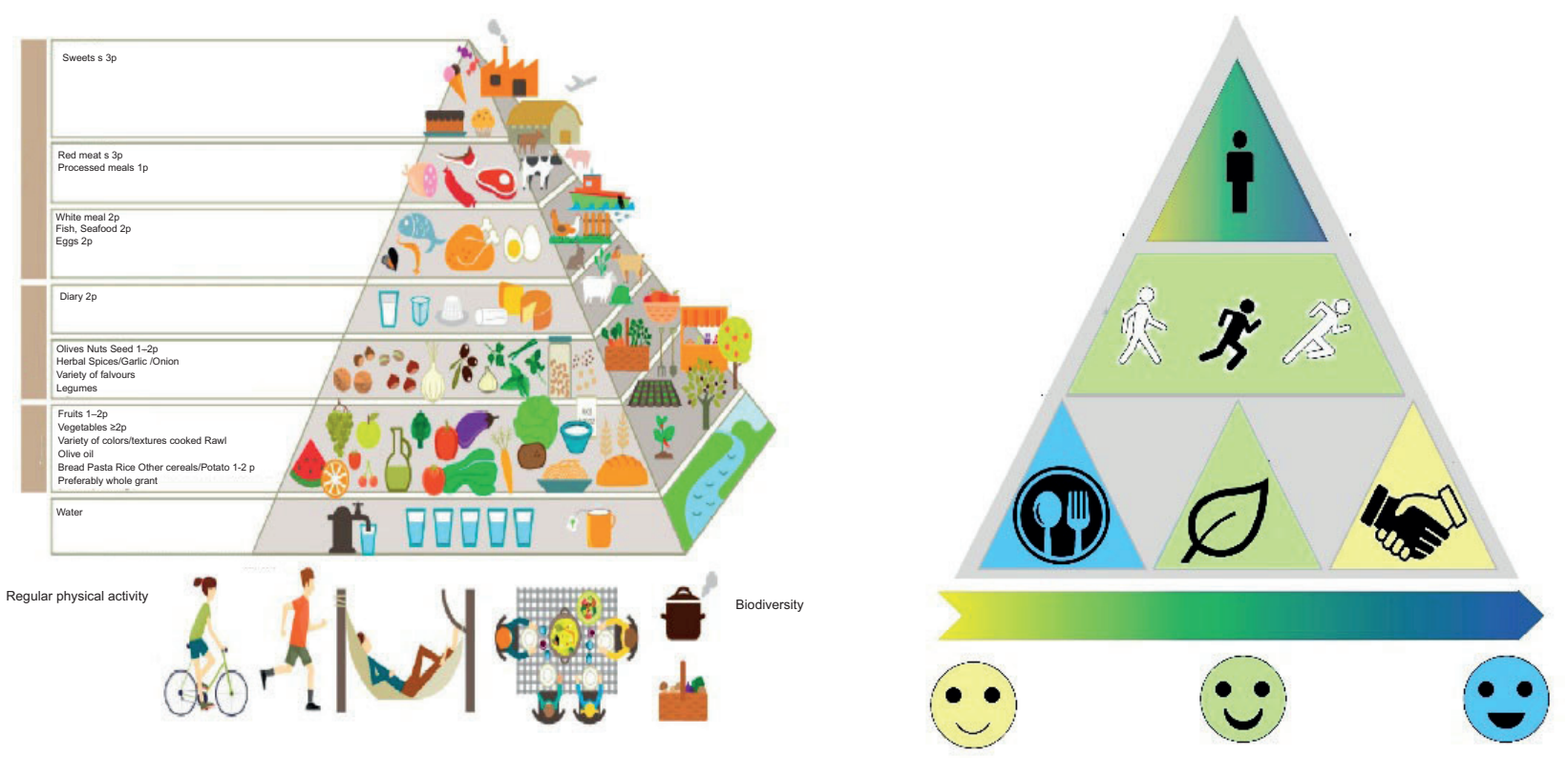

THE TRIANGLE IS IMMDIATELY ASSOCIATED WITH THE FOOD PYRAMID THAT EVOKES
THE CONCEPTS OF BALANCED FOOD CHOICES AND AIMED AT WELL-BEING
THE DIVISION INTO PARALLEL BANDS RECALLS THE ICONOGRAPHY OF THE FOOD PYRAMID

Figure 4. Med-index: the shape.
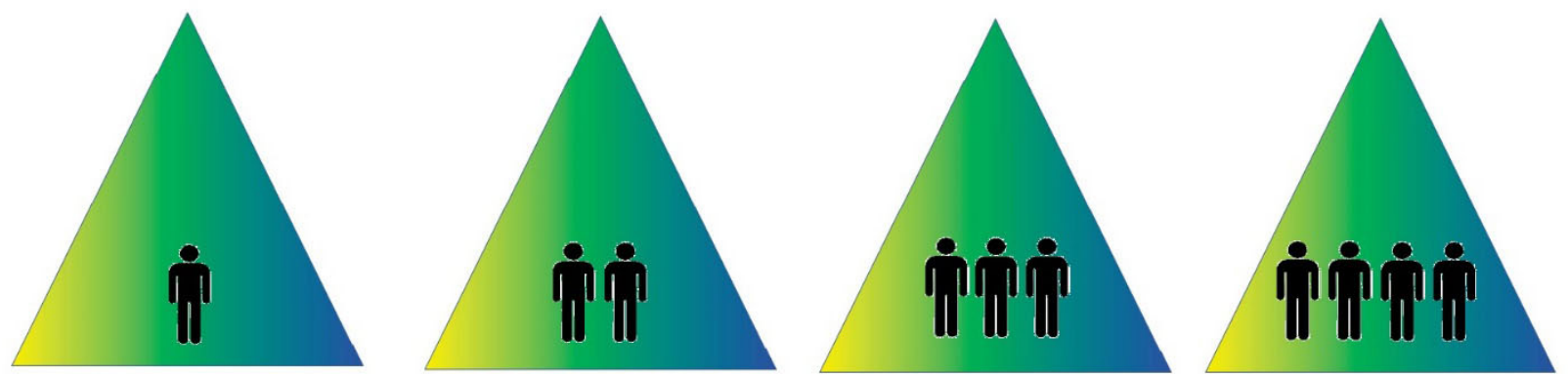

Figure 5. Med-index: apex of the triangle was intended to inform about the doses that make up the sales unit or the number of food portions.

the number of diners. The prescription of the portion in grams often represents an operational and psychological binding for diet compliance.

Obesity mostly affects individuals belonging to less affluent social classes associated with a lower level of education: culture, awareness, nutrition, and education are needed to fully understand the parameters chosen in most nutritional labels, often related to metabolic effects, and expressed in absolute or percentage numerical terms, which acquire meaning in a context of knowledge of the reference values. In the absence of skills, they do not contribute to positively changing food choices and behaviors.

While listing calories could have a detrimental effect on people with eating disorders, the caloric intake, instead of being expressed quantitatively through the number of $\mathrm{kcal}$, is expressed in the form of intensity of

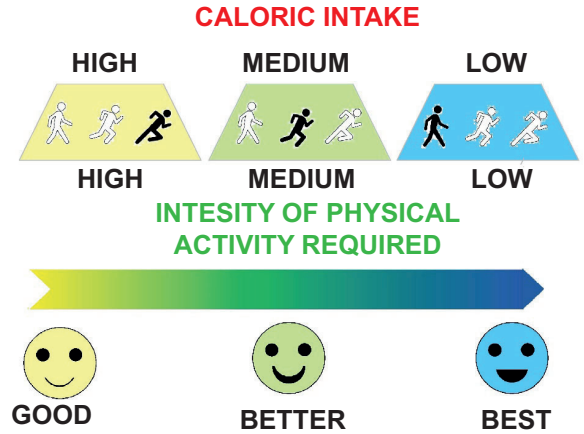

Figure 6. The central band of the triangle provides information on the calorie intake of the portion referring to the intensity of physical activity necessary to balance the intake of calories.

recommended physical activity (Figure 6), namely, low, medium, and high, so that a balance between calories consumed and calories ingested can be actuated, because it is necessary to strike a balance between informing and 
educating people to make healthier choices, while not negatively impacting people with eating disorders, or those in recovery. In fact, there is a broad consensus in the literature that a sedentary lifestyle is one of the main factors contributing to the epidemic of cardiometabolic diseases (Hill et al., 2012).

To make the communication clearer, three icons represent walking, light running, and intense running. The caloric intake is deduced from the icon highlighted in black and from the background color, which is in line with the color scale used to indicate the lowest caloric intake value with walking and the blue color which symbolizes the best choice, while the high caloric intake value with intense running is represented by the yellow color.

In addition to unhealthy diets, inadequate physical activity is an important factor in the increasing trend of obesity and noncommunicable diseases. The implementation of physical activity recommendations in nutrition labeling may influence the consumers' food choices. The MedIndex in full spirit of the principles of the Mediterranean diet encourages the practice of physical activity. Physical inactivity is in fact identified globally as the fourth most important risk factor for mortality. In many countries, levels of physical inactivity are increasing, with important repercussions on the prevalence of non-communicable diseases and on the state of health of the general population around the world.

The base of the triangle (Figure 7) provides information on the nutritional and sustainability characteristics of the product through the use of three small triangles that express the degree of nutritional, environmental, and social sustainability by means of three different colors.

This iconographic information is in line with the opinion of the European Economic and Social Committee (EESC,

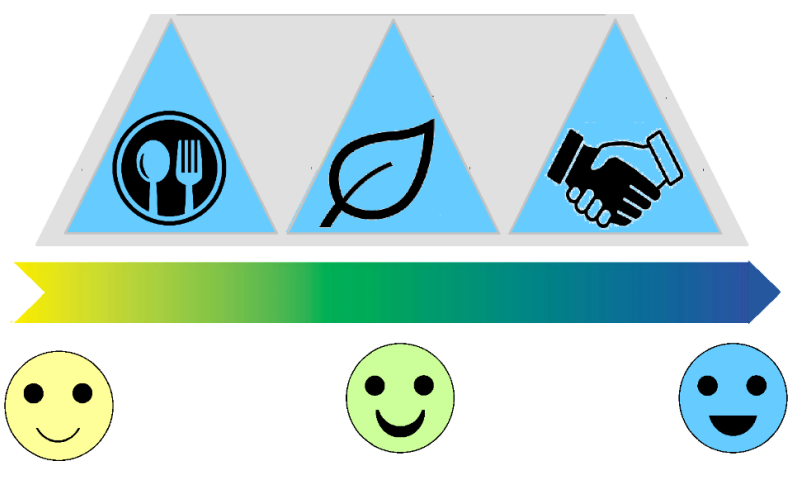

Figure 7. The base of the triangle provides information on the nutritional and sustainability characteristics of the product (NS: nutritional sustainability; ES: environmental sustainability; SS: social sustainability).
2017), a global EU food policy, adopted in December 2017 and then integrated in February 2019, with the released opinion entitled Promoting healthy and sustainable diets in the EU (EESC, 2019), which suggest combining healthy diets with environmental, social, and economic sustainability through the coordination of policy measures.

\section{Med-Index: The Colors}

The meaning of colors varies culturally. Traffic lights on the roads are different in Japan and Europe. The Japanese replace green with blue. Care must be taken when the message is intended for audiences from different nations as is the EU's intention to harmonize nutrition labeling; therefore, no proposal should be approved without a transnational pilot trial. Color is a real code, which changes from culture to culture.

In the Western society, these peculiarities are recognized in the main colors: in marketing, yellow is used to attract attention and convey optimism; red increases the heart rate, creates urgency and/or concern, and is an energetic color; blue creates the feeling of confidence and security; green is often a color that is easy to process for the eye, it provides relaxation because it does not weigh down the eyes; orange prompts action and is an aggressive color.

In the MI the colors are used to define a positive scale of values (Table 3) that excludes negative alarm signals as happens in the traffic light labeling when the red and orange colors appear that refer to the danger, generating an alert state. The message is always in a positive key because it starts from the assumption that the Med-Index

Table 3. The meaning of the colors used in the Med-index.

$\begin{array}{ll}\text { GOOD } & \begin{array}{l}\text { Yellow is the color of optimism and clarity; } \\ \text { it attracts attention and intrigues and can } \\ \text { arouse positive and reassuring emotions } \\ \text { (unlike red). } \\ \text { Green is the color of freshness, well-being, } \\ \text { and relaxation. It expresses authenticity and } \\ \text { naturalness and inspires confidence. } \\ \text { Blue is the color that most of all conveys } \\ \text { security, tranquility, and trust. It is a very } \\ \text { positive color, and it is also the color most } \\ \text { loved by people. }\end{array}\end{array}$


can only be applied to products that fall within the Mediterranean basket of products.

To support food security for current and future generations, there is a need to understand the relation between sustainable diets and the health of a population (Nelson et al., 2016). A set of criteria (Table 4) can be used to attribute color to the three triangles that will provide information on nutritional, environmental, and social sustainability.

If all the criteria of a category (e.g., good or better) are satisfied, even just one criterion of the next category (e.g., better or best) is sufficient for the triangle to take on the color of the best category. If for a category of sustainability, different from nutritional sustainability, no parameter is satisfied, the triangle remains white.

By way of example, Figure 8, summarizing the iconographic interpretation, shows the extremes of the value that the Med-Index can assume.

\section{An Index Consistent with the LARNs, the Pyramid of the Mediterranean Diet, and the Guidelines for Healthy Eating}

A balanced diet provides the right amounts of different nutrients to preserve the health and well-being of the body. Proteins, carbohydrates, fats, vitamins, minerals, and water are all "nutrients." Each nutrient has a specific function in the human body. The amount of each nutrient that is needed to keep an individual healthy is called the "nutrient

requirement." Nutrient requirements vary according to age and gender. The level of physical activity, the physiological state in which one is (e.g., pregnancy), dietary habits, and genetic heritage are also important factors.

Since eating in a healthy, balanced, and appropriate way, suitable to the individual well-being and energy expenditure, not only imply the choice of foods but also their quantity and frequency of consumption, it must be remembered that to follow a correct diet, it is essential to know how to quantify and evaluate the quality of what an individual eats.

The Med Index is a tool that used alone informs the consumer about the "standard portions," the specific quantity of a food taken as a reference unit of measurement and defined by experts for the main types of food groups, considering their content in nutritional principles, the average food consumption of the population, consistent with the food tradition and reported in the recent revision of the LARN (Nutrient and Energy Reference Intake Levels) (SINU, 2014). The LARN already in 1996, as well as in the last revision (2014), proposed a list of "measures for common use" for the quantification of standard portions, which the Med Index incorporates and typifies in iconographic form in the apical portion of the triangle.

To ensure proper nutrition, it is also necessary to establish how often (daily or weekly) a portion of a given food can or should be consumed according to different energy needs. Quantity and frequency of consumption must be adapted to age, sex, height, and level of physical activity.
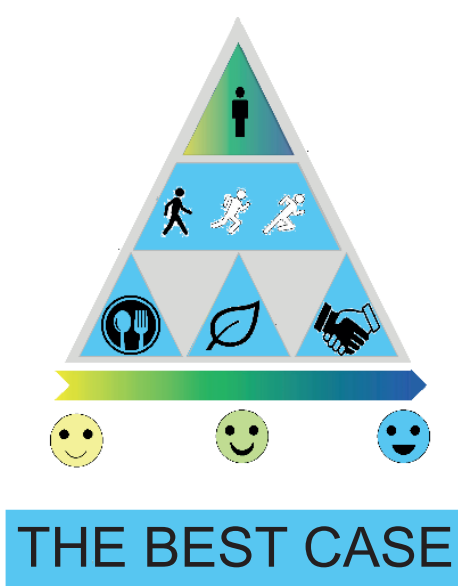

\section{THE GOOD CASE}

IT IS A TYPICAL PRODUCT OF THE MEDITERRANEAN DIET WITH A HIGH ENERGY SUPPLY PER PORTION THAT REQUIRES A HIGH INTENSITY PHYSICAL ACTIVITY TO BALANCE THE CALORIC SUPPLY
IT IS A TYPICAL PRODUCT OF THE MEDITERRANEAN DIET OBTAINED WITH RESPECT FOR THE ENVIRONMENT AND PEOPLE WITH A MODEST ENERGY SUPPLY PER PORTION THAT REQUIRES A PHYSICAL ACTIVTY OF LOW INTENSITY TO BALANCE THE CALORIC RATE

Figure 8. The extremes of the value that the Med-Index can assume. 
Table 4. Criteria for attributing, in each category of sustainability, nutritional, environmental, and social, the color that indicates the three degrees of positive evaluation, namely, good, better, and best.

\section{THE COLOR IS ATTRIBUTED ACCORDING TO THE PRESENCE OF AT LEAST ONE CHARACTERISTIC IN THE BEST CATEGORY}

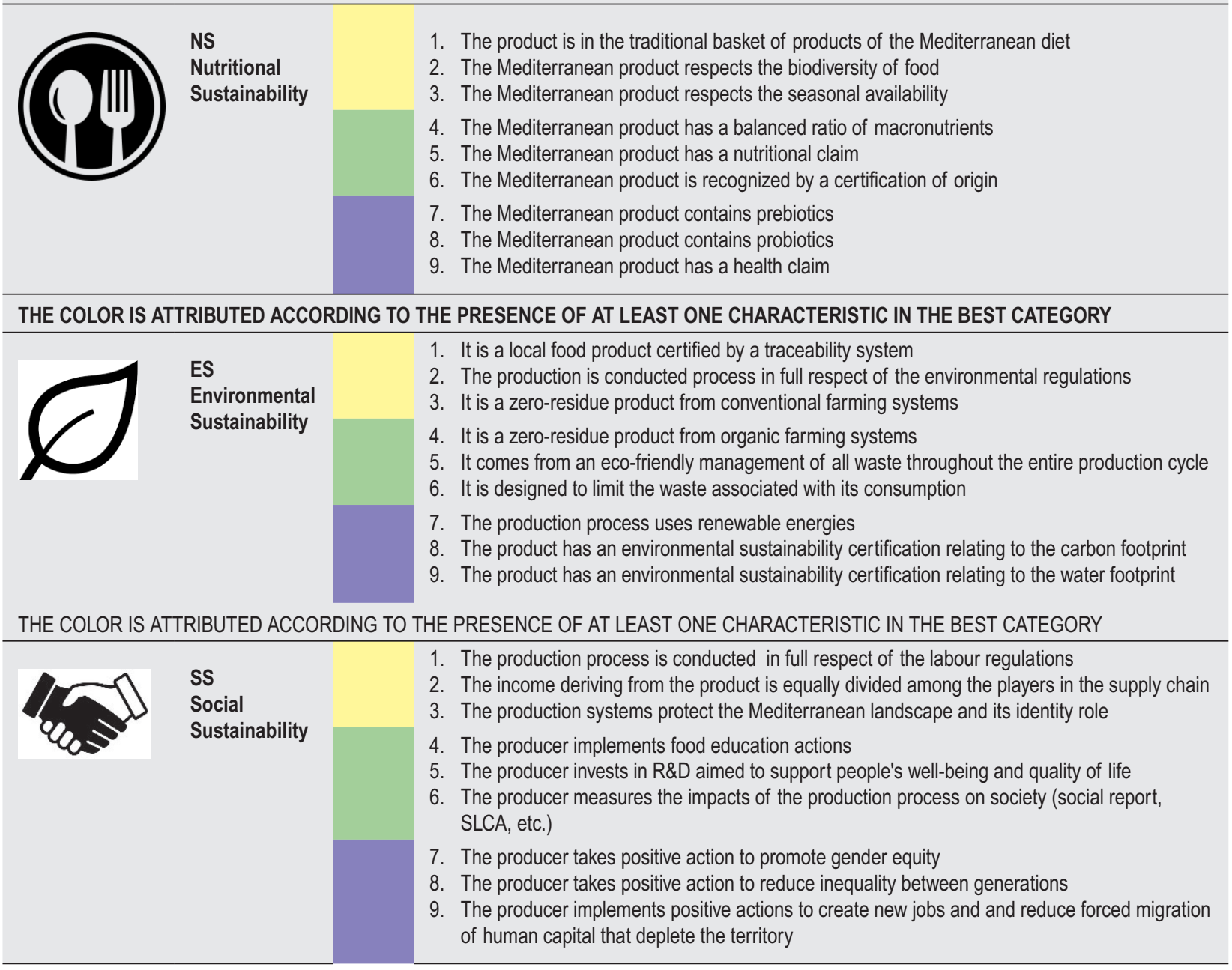

The Med Index combines with other tools such as the "Pyramid of the Mediterranean Diet" and the "Guidelines for healthy eating" to understand the "frequency of consumption of standard portions," which defines the number of standard portions recommended for each group (or subgroup/type) of foods to be consumed daily or weekly, to ensure the adequacy of the diet. The "Pyramid of the Mediterranean Diet" is a graphic symbol that shows with great immediacy which foods to consume, in what quantity, and how often to make them immediately understandable for the consumer.

Since the frequency of consumption cannot be the same for all individuals, but varies according to age, sex, physical activity, and physiological state, the "Guidelines for a healthy diet" address the needs:

(i) of woman in different stages of life, namely, fertile age, conception, pregnancy, and menopause;

(ii) of individuals in the age of growth, infants, children, and adolescents; (iii) of the elderly;

(iv) of sportsmen and athletes;

and in combination with the Med Index, it makes food purchasing choices more aware and immediate consistent with the "fast" lifestyle habits that reduce the time dedicated to food shopping and preparing meals.

\section{From Farm to Fork}

In the United Kingdom, large catering companies will need to display food calorie information on restaurant menus and on labels of prepackaged ready-to-eat food and ready meals sold in commercial establishments starting from April 2022, in order to make it easy for people to make healthier food choices for themselves and their families, both at the restaurant and at home. The obligation will apply to large companies with 250 or more employees in England, including bars, restaurants, and takeaways, which will have to indicate the calories of 
nonprepackaged food and nonalcoholic drinks prepared for customers. This information will need to be displayed on menus, including online menus, on food delivery platforms, and on food labels (Littlewood et al., 2016).

The Med-Index can be applied in all stages of the supply chain and to the different product ranges (Figure 9):

(i) Primary products: products of primary production including products from the land, livestock, hunting, and fishing.

(ii) Processed products: food products obtained from the processing of unprocessed products. These products may contain ingredients necessary for their processing or to give them specific characteristics.

(iii) Finished product: product that is not subjected to further processing or transformation by the company.

(iv) Gastronomic preparation: a complex of ingredients that has undergone a series of gastronomic preparation processes that are consumed at home, in collective catering, and in restaurants (Clodoveo et al., 2020).
This multi-sectoral and multilevel approach links food to education, agricultural practices, and different sources of sustainability and accountability.

\section{Extra Virgin Olive Oil: A Case Study}

Observational cohort studies and a secondary prevention trial have shown an inverse association between adherence to the Mediterranean diet and cardiovascular risk. PREDIMED researchers conducted a randomized trial of this diet pattern for the primary prevention of cardiovascular events. In this trial, an energy-unrestricted Mediterranean diet supplemented with either extra-virgin olive oil or nuts resulted in an absolute risk reduction of approximately three major cardiovascular events per 1000 person-years, for a relative risk reduction of approximately $30 \%$, among high-risk persons who were initially free of cardiovascular disease. These results support the benefits of the Mediterranean diet for cardiovascular risk reduction. They are particularly relevant given the challenges of achieving and maintaining weight loss.

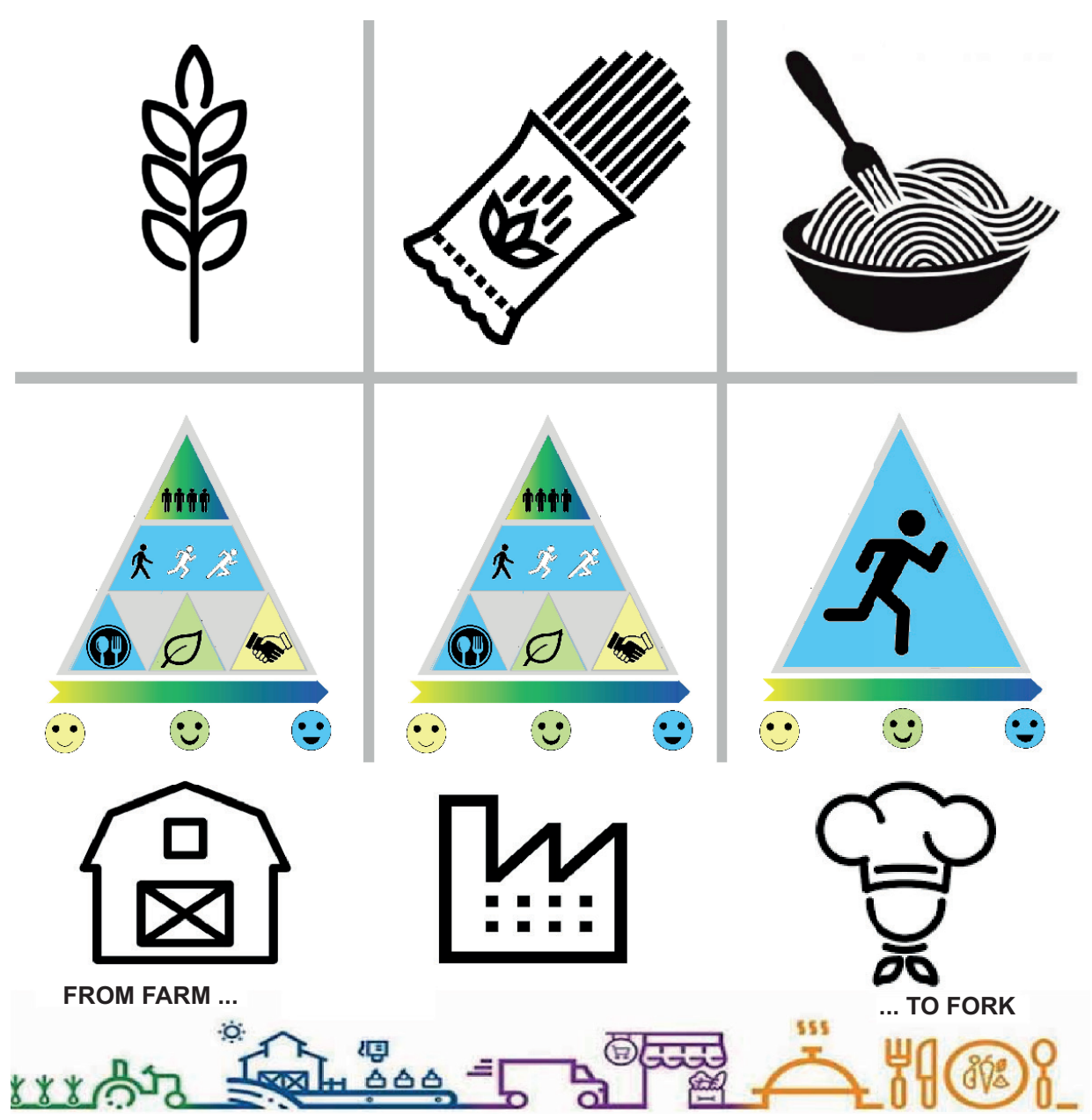

Figure 9. Applicability of Med-Index from farm to fork. 
The beneficial effects of EVOO (Lammi et al., 2020; Mallamaci et al., 2021) are not clearly communicated through the nutrition labels currently evaluated in the European harmonization process, in particular the NutriScore. In fact, Nutri-Score is calculated via an algorithm developed by a team of researchers, which combines both the nutrients to limit because considered unhealthy (i.e., calories, saturated fat, sugars and salt) and those elements to favor because considered healthy (such as fibers, proteins, nuts, fruit and vegetables) and thus should allow consumers to choose the healthy option comparing foods of the same category.

Under the system, extra virgin olive oil (EVOO) receives a yellow $\mathrm{C}$ rating. This, according to members of the olive oil industry, does not take the health benefits of EVOOs into due account and ultimately penalizes the product. Under this system, EVOO receives a yellow C rating. This, according to stakeholders of the olive oil industry, fails to account the health benefits of EVOOs (respect to refined olive oil and pomace olive oil, characterized by the same score) penalizing the image and the value of the product. Italian extra virgin olive oil producers believe that the Nutri score label on the front of the pack (FOPL) can't help European consumers understand the benefits of adhering to the Mediterranean diet because condemns EVOOs. Conversely, its simplistic classification could even turn citizens away from a food, the EVOO, that has so many scientifically proven health benefits. Conversely, its simplistic classification could even turn customers away from a food that has so many scientifically proven health benefits. Assitol, Italian Association of the Oil Industry, and many Italian olive oil producers believe that the possible introduction of Nutri-Score on domestic and foreign markets could hinder the extra virgin olive oil trade, especially in those countries where there is no native culture of the usage of olive oil that can compete with what they see as misleading information.

The Spanish National Designation of Origin Olive Oil Sector has requested that the Nutri-Score grant virgin and extra virgin olive oil the highest nutritional classification. This request received the support of the International Olive Oil Council (COI).

This request is not appropriate as it brackets extra virgin olive oil in the category of a mere commodity (Commodity is an economical term to identify a fungible product. This means that each unit of a commodity is considered exactly like every other unit, without element

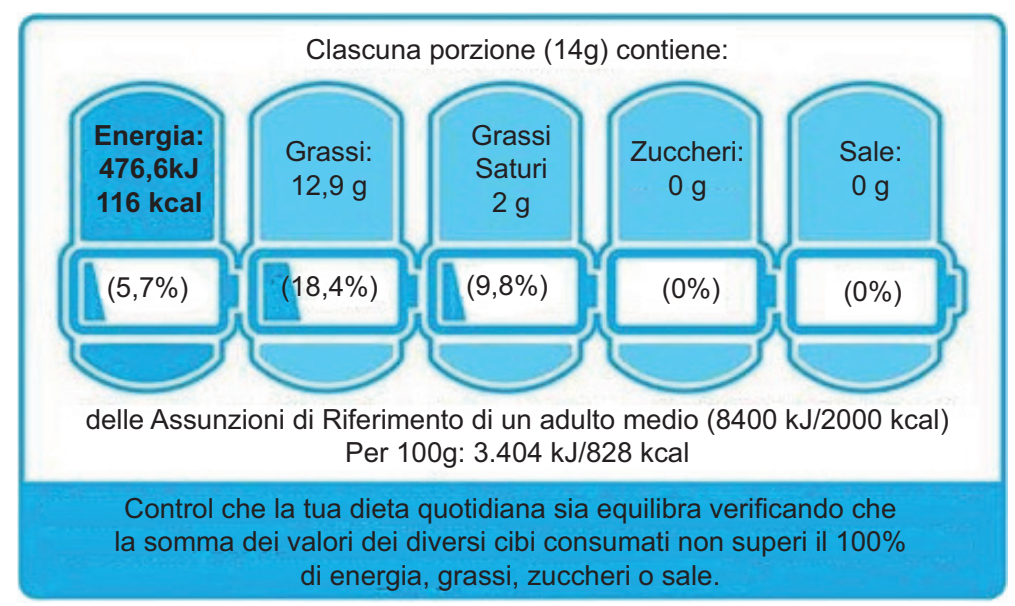

\section{NUTRI-SCORE}

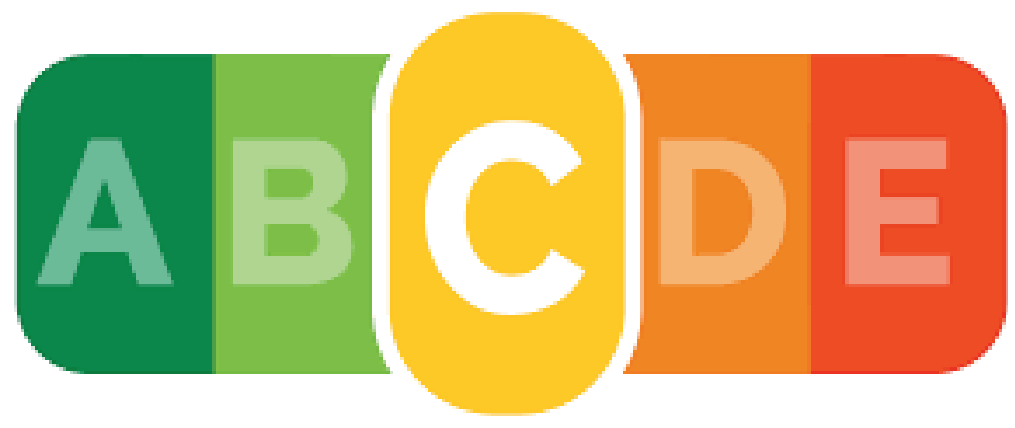

Figure 10. Nutrinform battery and Nutri-Score labels applied to extra virgin olive oil. 
Table 5. The Med index applied to two different types of extra virgin olive oil, an EVOO in promotion (A) and a high quality EVOO (B).

(A)

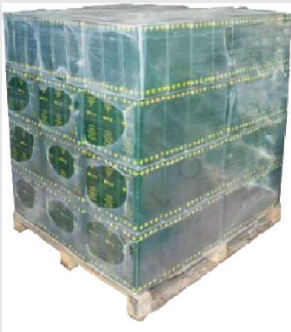

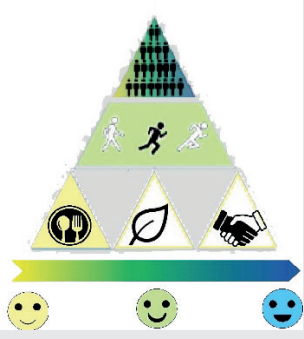

(B)

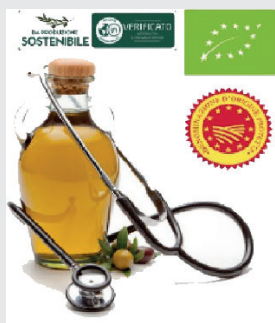

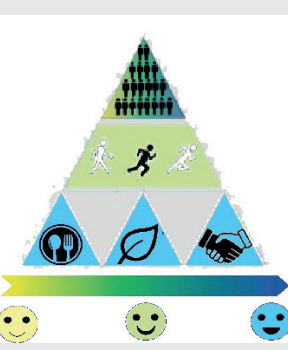

The Med Index of the EVOO in promotion (A) thanks to the iconographic code instantly delivers the following information to consumers: extra virgin olive oil is a condiment and as such the package contains numerous doses. The recommended daily dose, also by EFSA, $20 \mathrm{~g} /$ day, being made up of triglycerides, will require to be balanced by moderate intensity physical activity in order to achieve the balance between ingested calories and energy expenditure. While it does not have distinctive elements relating to certifications of origin, environmental or health claims, it is a good choice because extra virgin olive oil is the main lipid source in the basket of products suitable for the Mediterranean diet.
The high quality EVOO Med Index (B) thanks to the iconographic code instantly delivers the following information to consumers: extra virgin olive oil is a condiment and as such the package contains numerous doses. The recommended daily dose, also by EFSA, $20 \mathrm{~g} /$ day, being made up of triglycerides, will require to be balanced by moderate intensity physical activity in order to achieve the balance between ingested calories and energy expenditure. The product in question, extra virgin olive oil, in addition to being the main lipid source in the basket of products suitable for the Mediterranean diet, is equipped with numerous distinctive elements relating to certifications of origin (DOP), environmental certifications (it is an organic oil with sustainability certification) and reports three health claims (polyphenols, vitamin $\mathrm{E}$ and oleic acid), elements that overall make it the best choice, and in terms of value guarantee a premium price.

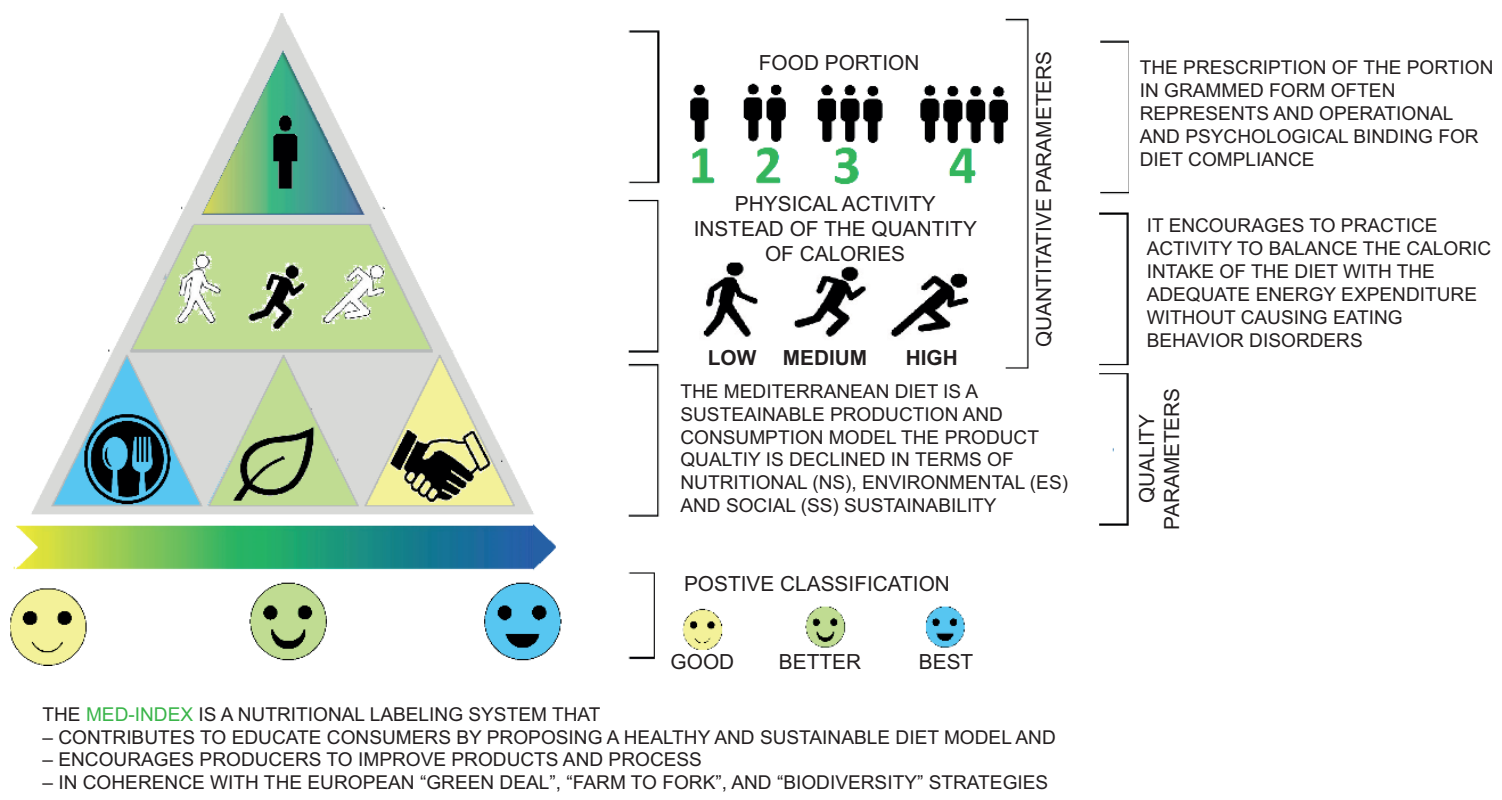

Figure 11. Med index graphic summary.

of differentiation that can determine a range of different values and prices, useful to award the best producer with a premium price). In fact, it perpetuates the misunderstanding that all extra virgin olive oils are the same from a health point of view. According to EFSA, the extra virgin olive oil, which is promoted for consumption as part of the Mediterranean diet for its beneficial effects against diseases of the cardiovascular system, is a product rich in oleic acid, polyphenols, and tocopherols.

This condition depends on the latitude of the production area, the variety of olives, and the agronomic and technological practices (Amirante et al., 2008, 2010a, $2010 \mathrm{~b}$ ); therefore, a nutritional label should allow the consumer to recognize with certainty an extra virgin oil that performs a mere function of condiment from the functional product, effective in reducing the risk of pathologies.

The Med-Index responds to this need in a complete and effective way and is a real food education tool that increases consumer awareness and encourages producers to improve the product and the process because it breaks the information asymmetry (Table 3) and facilitates in recognizing a premium price for the best product (Roselli et al., 2017). 


\section{Conclusions}

Citizens would benefit from extension to food nutritional labeling by including environmental and social information in order to drive consumers' choices toward healthier and more sustainable options (European Economic and Social Committee, 2019). The World Health Organization recommends member states to implement nutrition labels on packaging to guide citizens toward healthier food choices, as part of a comprehensive strategy to prevent noncommunicable food-related diseases. Overcoming these goals and integrating the objectives of Green Deal, in particular Farm to Fork and Biodiversity strategies, we have developed a food product labeling system, the Med-Index, which informs consumers not only by providing guidance on whether a food is good or bad for health but also as to whether the dietary choice can be both nutritious and sustainable. The use of the Med-Index, from Farm to Fork, can effectively create the conditions for Mediterranean food chains (farmers, processors, retailers, foodservice, and businesses) to produce, work, distribute, and sell healthier and more sustainable foods. The Med-Index is a positive label that guides consumers to the best choices.

The implementation of the Med-Index can create a constructive dialog with the industry because it is a simple and positive tool for consumers that can inform both on the quality aspects of food products and on the impact of the product production system.

The Med-Index supplements do not replace the Regulation (EU) No 1169/2011 that requires the vast majority of prepacked foods to bear a nutrition declaration providing the energy value and the amounts of fat, saturates, carbohydrate, sugars, protein, and salt of the food, with information presented in a legible tabular format on the packaging. In fact, the Med-Index wants to be inclusive, because it doesn't present monochrome numerical information that many consumers cannot understand and use like information to improve awareness in the choice, particularly those with lower nutrition literacy, education, or members of minority ethnic groups.

Med-Index can be useful to meet the present and future food needs of both citizens and the planet and can help citizens to shift food choices and patterns, stimulate companies to implement existing strategies, and help develop new agricultural production practices that reduce ecological effects and conserve resources while continuing to meet food and nutritional needs, thereby reducing food waste (Medina, 2019).

\section{Author Contributions}

Maria Lisa Clodoveo conceptualized the study, did the formal analysis, prepared the original draft, and created the graphic illustrations; Maria Lisa, Clodoveo, Elvira Tarsitano, and Filomena Corbo decided on the methodology of the study; Maria Lisa Clodoveo along with Elvira Tarsitano, and Filomena Corbo were involved in reviewing and editing; Supervision was done by Carlo Sabbà and Loreto Gesualdo; Maria Lisa Clodoveo and Filomena Corbo were in charge of project administration and funding acquisition. All authors have read and agreed to the published version of the manuscript.

\section{Funding}

This research was funded by The AGER 2 Project, grant no. 2016-0174, AGER Foundation-Olive Tree and Oil: Competitive-Claims of olive oil to improve the market value of the product; EU project 820587OLIVE-SOUND-Ultrasound reactor-The solution for a continuous olive oil extraction process H2020-EU.2.1.INDUSTRIAL LEADERSHIP-EIC-FTI-2018-2020-Fast Track to Innovation (FTI)-European Union's Horizon 2020 research and innovation program under grant agreement No. 820587.

\section{Conflicts of Interest}

The authors declare no conflicts of interest.

\section{References}

Amirante, P., Clodoveo, M.L., Leone, A., Tamborrino, A. and Patel, V.B., 2010a. Influence of different centrifugal extraction systems on antioxidant content and stability of virgin olive oil. In: Olives and olive oil in health and disease prevention. Academic Press, pp. 85-93.

Amirante, P., Clodoveo, M.L., Tamborrino, A., Leone, A. and Dugo, G., 2008. Oxygen concentration control during olive oil extraction process: a new system to emphasize the organoleptic and healthy properties of virgin olive oil. Acta Horticulturae 949: 473-480. https://doi.org/10.17660/ActaHortic.2012.949.70

Amirante, P., Clodoveo, M.L., Tamborrino, A., Leone, A. and Paice, A.G., 2010b. Influence of the crushing system: phenol content in virgin olive oil produced from whole and de-stoned pastes. In: Olives and olive oil in health and disease prevention. Academic Press, pp. 69-76.

Chakrabarti, S., Guha, S. and Majumder K., 2018. Food-derived bioactive peptides in human health: challenges and opportunities. Nutrients 10(11): 1738. https://doi.org/10.3390/nu10111738

Chantal, J., Hercberg, S. and World Health Organization, 2017. Development of a new front-of-pack nutrition label in France: the five-colour nutri-score. Public Health Panorama 3(4): 712-725.

Clodoveo, M.L., Di Lorenzo, L., Sabbă, C., Moschetta, A., Gesualdo, L. \& Corbo, F., 2020. The emerging discipline of precision cooking: a suitable tool for the precision nutrition. Int J 
Food Sci Nutr 71(4): 525-528. https://doi.org/10.1080/0963748 6.2019 .1679726

de Vries, H.J., 2020. Addressing sustainability in education about standardization - lessons from the Rotterdam School of Management, Erasmus University. In: Sustainable development. Springer, Cham, pp. 57-75.

Dernini, S. and Berry, E.M., 2015. Mediterranean diet: from a healthy diet to a sustainable dietary pattern. Front Nutr 2: 15. https://doi.org/10.3389/fnut.2015.00015

European Economic and Social Committee, 2019. ECO/481 Annual Growth Survey 2019. OPINION European Economic and Social Committee. Communication from the Commission to the European Parliament, the Council, the European Central Bank, the European Economic and Social Committee, the Committee of the Regions and the European Investment Bank - Annual Growth Survey 2019: For a stronger Europe in the face of global uncertainty [COM(2018) 770 final] Rapporteur: Anne DEMELENNE. [European Economic and Social Committee. ECO/481, 2019].

Frasca, D., Blomberg, B.B. and Paganelli, R., 2017. Aging, obesity, and inflammatory age-related diseases. Front Immunol 8: 1745. https://doi.org/10.3389/fimmu.2017.01745

Garrido-Miguel, M., Oliveira, A., Cavero-Redondo, I., Álvarez-Bueno, C., Pozuelo-Carrascosa, D.P., Soriano-Cano, A., et al., 2019. Prevalence of overweight and obesity among European preschool children: a systematic review and meta-regression by food group consumption. Nutrients 11(7): 1698. https://doi.org/10.3390/ nu11071698

Haines, A. and Scheelbeek, P., 2020. European green deal: a major opportunity for health improvement. Lancet 395(10233): 13271329. https://doi.org/10.1016/S0140-6736(20)30109-4.

Hill, J.O., Wyatt, H.R. and Peters, J.C., 2012. Energy balance and obesity. Circulation 126(1): 126-132. https://doi.org/10.1161/ CIRCULATIONAHA.111.087213

Joint WHO/FAO Expert Consultation, 2003. Diet, nutrition and the prevention of chronic diseases. World Health Organ Tech Rep Ser 916(i-viii): 1-149.

Julia, C. and Hercberg, S., 2018. Big food's opposition to the French nutri-score front-of-pack labeling warrants a global reaction. Am J Public Health 108(3): 318-320. https://doi.org/10.2105/ AJPH.2017.304284

Lammi, C., Bellumori, M., Cecchi, L., Bartolomei, M., Bollati, C., Clodoveo, M.L., et al., 2020. Extra virgin olive oil phenol extracts exert hypocholesterolemic effects through the modulation of the LDLR pathway: in vitro and cellular mechanism of action elucidation. Nutrients 12(6): 1723. https://doi.org/10.3390/nu12061723

Littlewood, J.A., Lourenço, S., Iversen, C.L., Hansen, G.L. Menu labelling is effective in reducing energy ordered and consumed: a systematic review and meta-analysis of recent studies. Public Health Nutr 19(12): 2106-2121. https://doi.org/10.1017/ S1368980015003468

Lorenzoni, G., Di Benedetto, R., Silano, M. and Gregori, D., 2021. What is the nutritional composition of ultra-processed food marketed in Italy? Nutrients 13(7): 2364. https://doi. org/10.3390/nu13072364

Machín, L., Aschemann-Witzel, J., Curutchet, M.R., Giménez, A. and Ares, G., 2018. Does front-of-pack nutrition information improve consumer ability to make healthful choices? Performance of warnings and the traffic light system in a simulated shopping experiment. Appetite 121: 55-62. https://doi.org/10.1016/j.appet.2017.10.037

Mallamaci, R., Budriesi, R., Clodoveo, M.L., Biotti, G., Micucci, M., Ragusa, A., et al. Olive tree in circular economy as a source of secondary metabolites active for human and animal health beyond oxidative stress and inflammation. Molecules 26(4): 1072. https://doi.org/10.3390/molecules 26041072

Martínez-González, M.A., Salas-Salvadó, J., Estruch, R., Corella, D., Fitó, M., Ros E., et al., 2015. Benefits of the Mediterranean diet: insights from the PREDIMED study. Prog Cardiovasc Dis 58(1): 50-60. https://doi.org/10.1016/j.pcad.2015.04.003

Medina, F.X., 2019. From healthy to sustainable: transforming the concept of the mediterranean diet from health to sustainability through culture. In: Collinson, P., Young, I., Antal, L. and Macbeth, H. (eds.), Food and sustainability in the twenty-first century: Cross-disciplinary perspectives. Berghahn Books, New York and Oxford, pp. 57-69.

Medina, F.X., 2021. Towards a construction of the Mediterranean diet? The building of a concept between health, sustainability and culture. Food Ethics 6(1): 1-10. https://doi.org/10.1007/ s41055-020-00083-4

Mhurchu, C.N., Eyles, H. and Choi, Y.H., 2017. Effects of a voluntary front-of-pack nutrition labelling system on packaged food reformulation: the health star rating system in New Zealand. Nutrients 9(8): 918. https://doi.org/10.3390/nu9080918

Narciso, A. and Fonte, M., 2021. Making farm-to-fork front-of-thepack: labelling a sustainable European diet. Int J Sociol Agricult Food 27(1): 54-70.

Nelson, M.E., Hamm, M.W., Hu, F.B., Abrams, S.A. and Griffin, T.S., 2016. Alignment of healthy dietary patterns and environmental sustainability: a systematic review. Adv Nutr 7(6): 1005-1025. https://doi.org/10.3945/an.116.012567

Piaggi, P., 2019. Metabolic determinants of weight gain in humans. Obesity 27(5): 691-699. https://doi.org/10.1002/oby.22456

Regulation (EC) No 1924/2006 of the European Parliament and of the Council of 20 December 2006 on nutrition and health claims made on foods. 2006. Official Journal of the European Union L404: 9-25.

Rescigno, T., Micolucci, L., Tecce, M.F. and Capasso, A., 2017. Bioactive nutrients and nutrigenomics in age-related diseases. Molecules 22(1): 105. https://doi.org/10.3390/molecules22010105

Romieu, I., Dossus, L., Barquera, S., Blottière, H.M., Franks, P.W., Gunter, M., et al. Energy balance and obesity: what are the main drivers? Cancer Causes Control 28(3): 247-258. https://doi. org/10.1007/s10552-017-0869-z

Roselli, L., Clodoveo, M.L., Corbo, F. and De Gennaro, B., 2017. Are health claims a useful tool to segment the category of extra-virgin olive oil? Threats and opportunities for the Italian olive oil supply chain. Trends Food Sci Technol 68: 176-181. https://doi. org/10.1016/j.tifs.2017.08.008

Serra-Majem, L., Tomaino, L., Dernini, S., Berry, E.M., Lairon, D., Ngo de la Cruz, J., et al. Updating the Mediterranean diet pyramid towards sustainability: focus on environmental concerns. Int J Environ Res Public Health 17(23): 8758. https://doi. org/10.3390/ijerph17238758 
Sikora, A., 2021. European green deal-legal and financial challenges of the climate change. ERA Forum 21(4): 681-697. https://doi. org/10.1007/s12027-020-00637-3

Tarsitano, E., Calvano, G., Sinibaldi, P. and Colao, M., 2018. Urban environmental education and sustainability in Lama Balice regional natural park. Int J Res Educ Stud 4: 10.

Tarsitano, E., Rosa, A.G., Posca, C., Petruzzi, G., Mundo, M. and Colao, M., 2020. A sustainable urban regeneration project to protect biodiversity. Urban Ecosyst 24(1): 1-18. https://doi. org/10.1007/s11252-020-01084-1

Toro-Martín, D., Arsenault, B.J., Després, J.P. and Vohl, M.C., 2017. Precision nutrition: a review of personalized nutritional approaches for the prevention and management of metabolic syndrome. Nutrients 9(8): 913. https://doi.org/10.3390/ nu9080913

Vamanu, E. and Gatea, F., 2020. Correlations between microbiota bioactivity and bioavailability of functional compounds: a mini-review. Biomedicines 8(2): 39. https://doi.org/10.3390/ biomedicines 8020039

van der Bend, D.L. and Lissner, L., 2019. Differences and similarities between front-of-pack nutrition labels in Europe: a comparison of functional and visual aspects. Nutrients 11(3): 626. https:// doi.org/10.3390/nu11030626 